Saudi Journal of Biomedical Research

Abbreviated Key Title: Saudi J Biomed Res ISSN 2518-3214 (Print) |ISSN 2518-3222 (Online)

\title{
Relation between Specific Gravity of Urine and Agoraphobia
}

Muhammad Imran Qadir, Manaal Khalid*

Institute of Molecular Biology and Biotechnology, Bahauddin Zakariya University, Multan, Pakistan

DOI:10.36348/SJBR.2019.v04i09.001

| Received: 07.09.2019 | Accepted: 14.09.2019 | Published: 30.09.2019

*Corresponding author: Manaal Khalid

\section{Abstract}

A condition in which a person feels uncomfortable in the crowded places, malls and using public transportation because he supposes himself unsafe in such places and imagines if an emergency situation occurs, no one will be there for his help thus leaving him helpless and embraced. Most of the time agoraphobia person is followed by panic attacks, in which person feels fast heartbeat rate, sweating, pressurized and even faintness occurs. It can be treated through counselling and proper medical checkups. Urinalysis is done in order to compare the level of specific gravity of urine with that of water for the purpose of monitoring any abnormality present in kidneys functioning. For this purpose dipstick test is done in this survey by dipping strips in the urine which changed their colour according to the intensity oof abnormality. After comparing the results we supposed there is some relation present in agoraphobia and urine specific gravity.

Keywords: Agoraphobia, dipstick test, specific gravity.

Copyright @ 2019: This is an open-access article distributed under the terms of the Creative Commons Attribution license which permits unrestricted use, distribution, and reproduction in any medium for non-commercial use (NonCommercial, or CC-BY-NC) provided the original author and source are credited.

\section{INTRODUCTION}

Agoraphobia is a condition in which a person suffers from mental disorder of fearing from rushed and open places as he considers himself insecure in such places[2]. Genetic factors with other environmental factors are the reason of such condition. Sometimes whole family suffers from this phobia due to some tragedy occurred with them in the past. Agoraphobic person avoids being in line, alls, funfairs or using public transports. Sometimes, this phobia is aided by panic attacks with rapid heartbeat, feeling pressurized, suffocation or even faintness. The treatment of this phobia is a little tricky but it can make person completely normal through proper counselling and taking regular medicines. Mainly it affects women at twice rate as compared to men. Usually adults between17-30 are in its influence and if they are left untreated they even become depressed, being drug addicted or even may develop other mental disorders.

Kidneys are one of the most important organs of our body as they filter our blood, remove excessive wastes from our body and maintain normal electrolyte balance which is necessary for proper functioning of body. A number of tests are available to check the proper functioning of kidneys. One of them is a urine specific gravity test which includes process of comparing specific gravity of urine with the gravity of water in order to check the medical condition of our internal body. This test also indicates how perfectly our kidneys are diluting the urine. If test shows that urine is much concentrated. It may be due to improper function of kidneys or not drinking enough water. If urine is less concentrated it indicates the presence of Diabetes Insipidus, in which urine excretes in diluted amount causing more thirst. This test is performed by cleancatch method followed by osmolarity test to evaluate how kidneys dilute or concentrate urine, with osmolarity being the index of concentration.

\section{MATERIALS AND METHODOLOGY}

For finding specific gravity of urine level, one should perform urine test. Usually this test is performed though dip stick test[1]. In this test strips containing ten boxes for checking level different components in urine are used. Usually paper or rubber material is used in the formation of strips. Before performing dip stick test, we made random selection of 100 students and instructed all students to fill $3^{\text {rd }}$ part of urine cup with urine. Materials used are gloves, masks, urine container and strips box. Then we generally analyzed the condition and smell of urine. After this we dipped a strip into urine and after few seconds we isolated it and removed extra urine by tapping on the corner of container, then we waited for some time to make the strips to change its colour by placing it horizontally. If there is some abnormality, the strip changes its colour. Then colour appeared on strip was compared with colour scale provided by the company. Then all the obtained values 
were written on the sheet and table was drawn

accordingly to check the significance of results.

Table-1: Association between Agoraphobia and Specific gravity

\begin{tabular}{|l|l|l|l|l|}
\hline Sr. number & Gender & Presence of agoraphobia & Absence of agoraphobia & P vale \\
\hline 1 & Male & $1.02 \pm 0.009$ & $1.02 \pm 0.007$ & $0.1^{*}$ \\
\hline 2 & Female & $0.91 \pm 0.30$ & $0.85 \pm 0.36$ & $0.4^{*}$ \\
\hline 3 & Both & $1.02 \pm 0.006$ & $0.9 \pm 0.30$ & $0.4^{*}$ \\
\hline
\end{tabular}

\section{RESULTS}

As the values of TTEST are more than 0.1 so it shows no significant results.

\section{CONCLUSION}

It is concluded that there is some relation present between agoraphobia and specific gravity of urine.

\section{REFERENCES}

1. Devillé, W. L., Yzermans, J. C., Van Duijn, N. P., Bezemer, P. D., Van Der Windt, D. A., \& Bouter, L. M. (2004). The urine dipstick test useful to rule out infections. A meta-analysis of the accuracy. BMC urology, 4(1), 4.

2. Goldstein, A. J., \& Chambless, D. L. (1978). A reanalysis of agoraphobia. Behavior Therapy. 